\title{
Electroacupuncture reduces $A \beta$ production and BACE1 expression in SAMP8 mice
}

\author{
Wei-Guo Dong ${ }^{1 *}$, Feng Wang ${ }^{1}$, Ye Chen ${ }^{1}$, Xue-Hua Zheng ${ }^{1}$, Yong-Cai Xie ${ }^{1}$, Wan-Qing Guo ${ }^{2}$ \\ and Hong Shi ${ }^{1}$ \\ ${ }^{1}$ Department of Integrated Traditional Chinese and Western Medicine, Fujian University of Traditional Chinese Medicine, Fuzhou, \\ China, ${ }^{2}$ The Third People's Hospital of Fujian Province, Fuzhou, China
}

OPEN ACCESS

Edited by:

Alessandro Martorana,

Rome University Tor Vergata, Italy

Reviewed by:

Alessandro Martorana

Rome University Tor Vergata, Italy

Francesco Di Lorenzo,

Fondazione Santa Lucia, Italy

Roberta Semprini,

ACISMOM Centro Diabetologico,

Italy

*Correspondence:

Wei-Guo Dong

Department of Integrated

Traditional Chinese and Western

Medicine, Fujian University of

Traditional Chinese Medicine,

1 Qiuyang Road, Minhou Shangjie,

Fuzhou, Fujian 350122, China

fjdwg601@163.com

Received: 01 February 2015

Accepted: 15 July 2015

Published: 29 July 2015

Citation:

Dong W-G, Wang F, Chen Y, Zheng $X-H$, Xie $Y-C$, Guo $W-Q$ and

Shi $H$ (2015) Electroacupuncture reduces $A \beta$ production and $B A C E 1$

expression in SAMP8 mice.

Front. Aging Neurosci. 7:148.

doi: 10.3389/fnagi.2015.00148
Electroacupuncture (EA) has been reported to have beneficial effects on Alzheimer's disease (AD). BACE1 ( $\beta$-site amyloid precursor protein-cleaving enzyme 1 ) is involved in the abnormal production of amyloid- $\beta$ plaque $(A \beta)$, a hallmark of $A D$ pathophysiology. Thus, the present study investigated the effects of EA on memory impairment, $A \beta$ production, and BACE1 expression in senescence-accelerated mouse prone 8 (SAMP8) mice. We found that EA improved spatial learning and memory impairment of SAMP8 mice. Furthermore, EA attenuated $A \beta$ production and repressed the expression of BACE1 in the hippocampus of SAMP8 mice. Taken together, our results suggest that EA could have a potential therapeutic application in $A D$ and that BACE1 may be an important target of $E A$ in the treatment of $A D$.

Keywords: Alzheimer's disease, electroacupuncture, memory impairment, BACE1, amyloid- $\beta$

\section{Introduction}

Alzheimer's disease (AD) is a progressive neurodegenerative disease characterized by two neuropathological hallmarks: extracellular senile plaque deposits, composed of amyloid $\beta$-peptide $(A \beta)$, and intracellular neurofibrillary tangles. Ample evidence indicates that $A \beta$ plays a central role in AD pathogenesis (Hardy and Selkoe, 2002; Selkoe and Schenk, 2003; Zhang and Xu, 2007). A $\beta$ is generated after the cleavage of amyloid precursor protein (APP) by the $\beta$-secretase [ $\beta$-site amyloid precursor protein-cleaving enzyme 1 (BACE1), $\beta$-site APP cleaving enzyme 1$]$, and $\gamma$-secretase complex (Hardy and Selkoe, 2002). In addition, BACE1 expression and activity levels are increased in $\mathrm{AD}$ brains and correlate with specific regions affected by $\mathrm{A} \beta$ deposition (Fukumoto et al., 2002; Holsinger et al., 2002; Li et al., 2004; Harada et al., 2006; Coulson et al., 2010). Targeting BACE1 with small interfering RNA (siRNA) and BACE1 gene deletion reduces $\mathrm{A} \beta$ levels and prevents learning and memory impairment in a mouse model of AD (Ohno et al., 2004; Singer et al., 2005). Thus, BACE1 is considered a promising target for prevention or modification of AD (Li et al., 2006; Menting and Claassen, 2014). Moreover, several BACE1 inhibitors have entered clinical trials (Yan and Vassar, 2014).

Abbreviations: $A D$, Alzheimer's disease; $A \beta$, amyloid $\beta$-peptide; $B A C E 1, \beta$-site amyloid precursor protein-cleaving enzyme 1 EA, electroacupuncture; ELISA, enzyme-linked immunosorbent assay; GAPDH, glyceraldehyde-3-phosphate dehydrogenase; MWM, Morris water maze; PGC- $1 \alpha$, peroxisome proliferator-activated receptor- $\gamma$ co-activator- $1 \alpha$; qRT-PCR, quantitative real-time reverse transcription polymerase chain reaction; SAMP8, senescence-accelerated mouse prone 8; SAMR1, senescence-accelerated-resistant mouse 1; siRNA, small interfering RNA; SIRT1, Sirtuin 1. 
The senescence-accelerated mouse prone 8 (SAMP8) strain is a spontaneous animal model of accelerated aging. SAMP8 mice exhibit cognitive and behavioral alterations and neuropathological abnormalities observed in patients with $\mathrm{AD}$, such as deficits in learning and memory, $\mathrm{A} \beta$ deposits, and tau phosphorylation (Pallas et al., 2008; Takeda, 2009; Manich et al., 2011). Thus, SAMP8 mice have been proposed as an excellent model for exploring the pathophysiological mechanism of sporadic $\mathrm{AD}$ and a plausible experimental model for developing preventative and therapeutic treatments for late-onset/age-related $\mathrm{AD}$, which accounts for the vast majority of cases in humans (Cheng et al., 2014; Bayod et al., 2015). Senescence-accelerated resistant mouse 1 (SAMR1), which has a genetic background similar to that of SAMP8, does not exhibit these senescence-related neuronal phenotypes and has been used extensively as a control strain (Takeda, 1999, 2009). In addition, BACE1 protein levels and activity were increased in SAMP8 mice compared with age-matched SAMR1 mice (Zhou et al., 2012; Orejana et al., 2015).

Acupuncture penetrates the skin with needles and stimulates specific points on the body. It has long been used for the treatment of many diseases. Electroacupuncture (EA) is a reformative form of traditional acupuncture that is accepted by Western countries due to its reproducibility (Chon and Lee, 2013). EA or acupuncture has been shown to improve cognitive deficits in animal models of AD (Cheng et al., 2008; Li et al., 2012, 2014; Wang et al., 2014a). Moreover, acupuncture activates specific cognitive-related regions and enhances hippocampal connectivity in AD patients (Wang et al., 2012, 2014c). Our previous studies demonstrated that EA at Dazhui (GV14) and Shenshu (BL23) in SAMP8 mice improves cognitive deficits, activates AMP-activated protein kinase (AMPK), and upregulates Sirtuin 1 (SIRT1)-dependent peroxisome proliferator- activated receptor$\gamma$ co-activator-1 $\alpha$ (PGC-1 $\alpha$ ) expression (Dong et al., 2015). A recent study showed that the SIRT1-PPAR $\gamma$-PGC-1 pathway may regulate BACE1 expression under metabolic stress conditions (Wang et al., 2013). Both activation of the SIRT1 signaling pathway and PGC- $1 \alpha$ overexpression attenuate BACE1 expression and $A \beta$ levels (Katsouri et al., 2011; Marwarha et al., 2014). On the basis of these studies, we speculate that EA may reduce the expression BACE1 and consequently reduces $A \beta$ levels.

In this study, we evaluated the effects of EA on spatial learning and memory impairment in SAMP8 mice. Furthermore, we examined the effects of EA on $\mathrm{A} \beta$ production and BACE1 expression.

\section{Materials and Methods}

\section{Animals and Groups}

This study utilized 32 male SAMP8 mice and 16 male homologous SAMR1 mice ( 7 months of age), which are provided by the Department of Laboratory Animal Science of Peking University. There was no difference between their baseline ages. All mice were housed under standard conditions at $22 \pm 2^{\circ} \mathrm{C}$ and a $12 \mathrm{~h}$ light/dark cycle with free access to food and water throughout the entire study. The mice were randomly assigned to the following three groups ( $n=16$ /group): SAMR1 normal control group (Rc), SAMP8 control group (Pc), and SAMP8 EA group (Pe). Mice in the Pe group received EA administration, while mice in the Rc and
Pc groups were grasped for the same amount of time and with the same extent of strength as mice in the Pe group. Moreover, mice in the Rc and Pc groups were restrained in nets for the same length of time as mice in the Pe group. All experimental procedures were approved by the Ethical Committee of Fujian University of Traditional Chinese Medicine and were performed according to the internationally accepted principles for laboratory animal use and care. We made all efforts to minimize the animal suffering in the study.

\section{EA Treatment}

Electroacupuncture treatment was performed as described in our previous study (Dong et al., 2015). Briefly, we used nets to fix the mice by the assistant's hands during the entire treatment. Three stainless steel acupuncture needles of $0.25 \mathrm{~mm}$ in diameter were inserted at a depth of approximately $5 \mathrm{~mm}$ into the "Dazhui" acupoint (GV14, below the spinous process of the seventh cervical vertebra) and the bilateral "Shenshu" acupoint (BL23, at the depression lateral to the lower border of the spinous process of the second lumbar vertebra). The acupoint location in the mouse is mainly in accordance with the transpositional method, which locates the animal acupoints on the surface of the animal's skin, corresponding to the anatomical site of the human acupoint. Thus, the anatomical site and location of Dazhui in both humans and mice are the same, and are located below the spinous process of the seventh cervical vertebra. Shenshu in humans is located 1.5 cun lateral to the lower border of the spinous process of the second lumbar vertebra. On the basis of the transpositional method, Shenshu in a mouse is located at the depression lateral to the lower border of the spinous process of the second lumbar vertebra. Needles at GV14 and the side BL23 were connected to the output terminals of the EA instrument (Hwato, model No. SDZV, Suzhou Medical Instruments Co., Ltd., Suzhou, China) and bilateral BL23 was alternated. We performed continuous-wave stimulation at a frequency of $2 \mathrm{~Hz}$ (intensity $1 \mathrm{~mA}$ ). An individual EA session was administered daily for $20 \mathrm{~min}$, for 8 days, with 2 days of rest, for a period of 30 days. Each treatment for all the mice has been performed at the same day and the same time point during EA treatment.

\section{Morris Water Maze Test}

At the end of the 30 days of EA treatment, mice were tested for spatial learning and memory in the Morris water maze (MWM). The apparatus consisted of a large circle tank $(120 \mathrm{~cm}$ in diameter, $30 \mathrm{~cm}$ in height) and was filled with opaque water $\left(21-23^{\circ} \mathrm{C}\right)$ with white milk. The pool was divided into four quadrants of equal area. A platform $(10 \mathrm{~cm}$ in diameter) was placed $1 \mathrm{~cm}$ below the water surface at the midpoint of one of the four quadrants. The position of the platform was unchanged during the training session. Before the acquisition training session, a visible platform test was performed, which confirmed that there were no significant differences in sensory, motor, or motivational activities among these three groups. Next, a hidden platform test was performed in succession. The paradigm consisted of four trials per day over five consecutive days in which the mice were placed at one of four different start positions for each trial and given $90 \mathrm{~s}$ to locate the hidden platform. In each trial, the escape latency was defined 
as the time a mouse spent from being placed into the water to finding and climbing onto the hidden platform. If a mouse failed to locate the platform within $90 \mathrm{~s}$, then it was gently guided onto the platform and allowed to remain there for $10 \mathrm{~s}$, and its escape latency was recorded as $90 \mathrm{~s}$. Retention memory was evaluated on probe trials presented on day 6 . During the probe trial, the platform was removed from the pool. The mice were released into the water on the opposite side of the target quadrant and were allowed to swim freely for $60 \mathrm{~s}$. The total number of times that each mouse crossed the position where the platform was once placed and the time that it spent in the target quadrant and opposite target were recorded.

\section{Tissue Collection}

At the end of the MWM test, mice were anesthetized intraperitoneally (i.p.) with $10 \%$ chloral hydrate $(100 \mathrm{~g} / 0.35 \mathrm{~mL})$ and immediately perfused transcardially with $50 \mathrm{~mL}$ of phosphatebuffered saline (PBS). The brains were immediately removed and the hippocampi were then isolated, frozen on powdered dry ice, and stored at $-80^{\circ} \mathrm{C}$ until further assay.

\section{Western Blotting Analysis}

Frozen hippocampi were homogenized in RIPA buffer supplemented with protease inhibitor cocktail and centrifuged at $12,000 \times g$ for $20 \mathrm{~min}$ at $4^{\circ} \mathrm{C}$. The supernatants were collected, and total protein levels were quantified using a BCA protein assay kit (Beyotime, Haimen, Jiangsu, China). Equal amounts $(30 \mu \mathrm{g})$ of each sample were separated on $10 \%$ SDS-polyacrylamide gels. After electrophoresis, the proteins were transferred onto a nitrocellulose membrane (Millipore) at $100 \mathrm{~V}$ for $60 \mathrm{~min}$ on ice. The membrane was blocked with $5 \% \mathrm{w} / \mathrm{v}$ non-fat dry milk powder in Tris-buffered saline with $0.05 \%$ Tween 20 (TBS-T) for $1 \mathrm{~h}$. After blocking, membranes were incubated with the primary antibodies overnight at $4^{\circ} \mathrm{C}$. The following primary antibodies were used: anti-A $\beta$ (6E10, 1:1000, Covance), rabbit polyclonal anti-BACE1 (1:1000, Sigma), and anti- $\beta$-actin (1:5000, Sigma). Immunoreactive bands were detected with HRP-conjugated goat anti-rabbit IgG (1:2000, Santa Cruz Biotechnology). The membrane was washed with TBS-T and the immunocomplex was visualized using an enhanced chemiluminescence detection kit (Thermo Scientific, Rockford, IL, USA). Signals of the membrane were scanned using the FluorChem Scanner and quantified using NIH Image J software. These results were normalized against $\beta$ actin expression levels and confirmed by triplicate measurements of the same sample.

\section{Determination of $A \beta$ Levels by Enzyme-Linked Immunosorbent Assay}

For human A $\beta 1-42$ levels detection, frozen hippocampal samples were homogenized in $5 \mathrm{M}$ guanidine hydrochloride, and centrifuged at $16,000 \times g$ for $20 \mathrm{~min}$ at $4^{\circ} \mathrm{C}$. The supernatant was collected and diluted with dilution buffer plus protease inhibitor cocktail. Levels of $A \beta 1-42$ were measured using a human $A \beta 1$ 42 Enzyme-linked immunosorbent assay (ELISA) kit (Invitrogen) according to the manufacturer's instructions. The absorbance was read at $450 \mathrm{~nm}$ using a 96-well plate reader, and A $\beta 1-42$ levels were calculated from a standard curve and normalized against total protein levels, as determined using the BCA protein assay kit.

\section{Quantitative Real-Time Reverse Transcription Polymerase Chain Reaction}

Total RNA was isolated using the RNeasy Mini Kit (Qiagen). Next, cDNA was synthesized using the TaqMan reverse transcription reagents kit (Applied Biosystems) and real-time PCR was performed on a 7300 real-time PCR system (Applied Biosystems, CA, USA) using the SYBR Green PCR master mix (Applied Biosystems) according to the manufacturer's instructions. The primers used for real-time PCR were the following: BACE1 forward: $5^{\prime}$-CCGGCGGGAGTGGTATTATGAAGT-3', reverse: $5^{\prime}$-GATGGTGATGCGGAAGGACTGATT-3'; GAPDH forward: 5'-TGGAAAGCT GTGGCGTGAT-3', reverse: $5^{\prime}$ TGCTTCACCACCTTCTTGAT- $3^{\prime}$. The data were analyzed according to the delta-delta $\mathrm{Ct}(\Delta \Delta \mathrm{CT})$ method and were normalized against GAPDH expression in each sample.

\section{Statistical Analysis}

The results are expressed as the mean \pm SEM. The escape latency of mice in the MWM test was analyzed using two-way analysis of variance (ANOVA) for repeated measurement. Tukey's test was further used as a post hoc test to detect between-group differences. One-way ANOVA was employed to analyze other data obtained in these experiments followed by LSD (equal variances assumed) or Dunnett's T3 (equal variances not assumed) for the post hoc test between groups. $P<0.05$ was considered statistically significant.

\section{Results}

\section{Effect of EA on Memory Impairment in SAMP8 Mice in the MWM Test}

The MWM test was performed to detect the effect of EA on spatial learning and memory ability. The escape latency during acquisition training is shown in Figure 1A. The escape latency in the hidden platform acquisition phase decreased with an increase in the training day. Compared to Rc mice, Pc mice exhibited significantly longer escape latencies in the training session. EA significantly shortened the escape latency in SAMP8 mice. However, swimming speed was not significantly different among these groups (Figure 1B). After the training test, the probe test was performed to analyze the maintenance of memory. Pc mice exhibited a trend toward decreased time spent in the target quadrant and opposite quadrant compared with Rc mice, and EA increased the time spent by SAMP8 mice in the target quadrant and opposite quadrant (Figures 1C,D). In addition, the number of platform crossings was significantly reduced in Pc mice compared with Rc mice, and EA increased the number of platform crossings in SAMP8 mice (Figure 1E). Taken together, these results indicated that spatial learning and memory were impaired in SAMP8 mice and that EA could improve this cognitive impairment.

\section{EA Treatment Inhibits $A \beta$ Production in the SAMP8 Mouse Hippocampus}

To investigate the effects of EA on $A \beta$ production in the SAMP8 mouse brain, we used western blotting analysis for $A \beta$ and ELISA for $A \beta 1-42$. Western blotting analysis showed that $A \beta$ expression was increased in the hippocampus of SAMP8 mice compared 

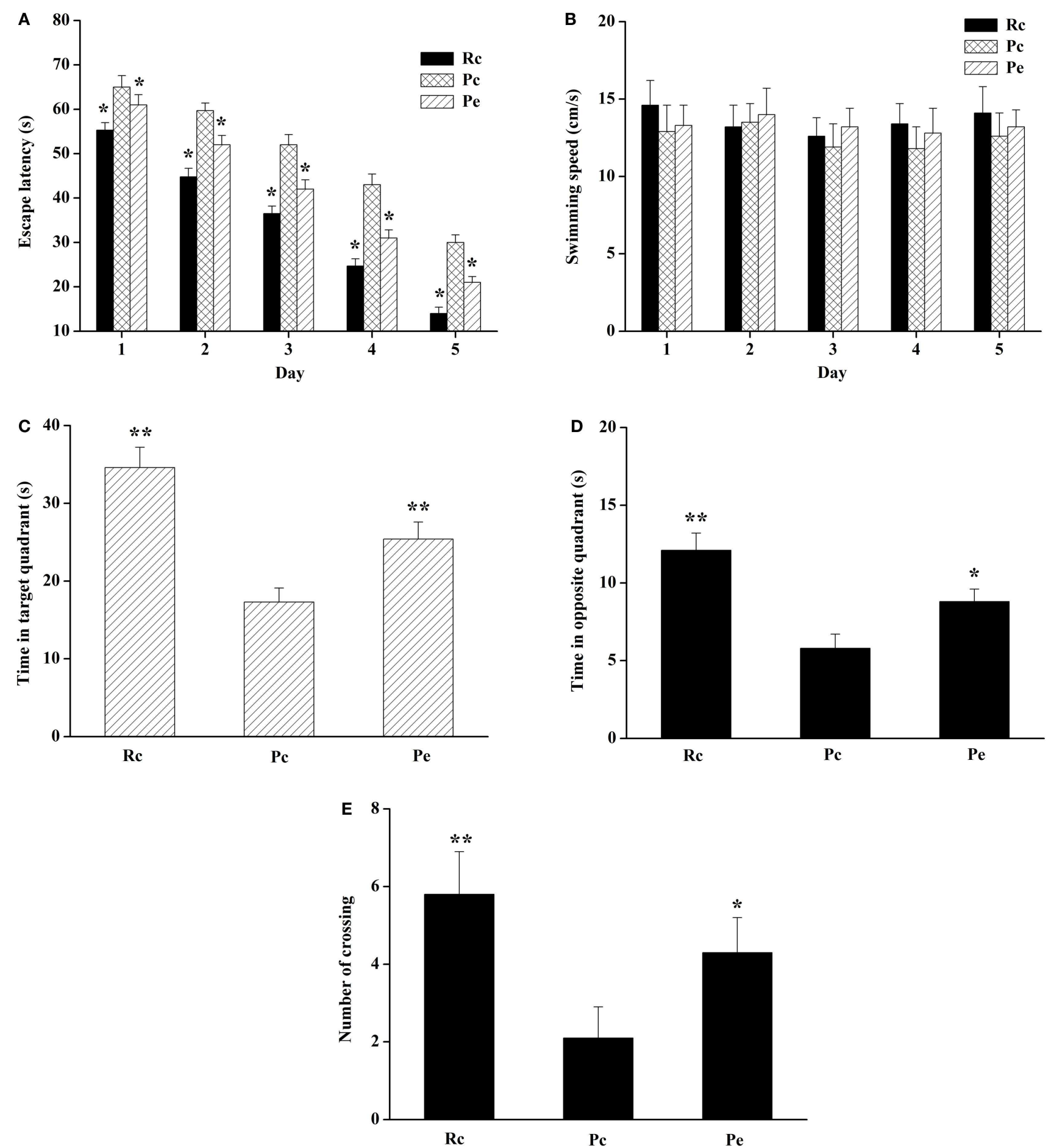

FIGURE 1 | Effects of EA on spatial learning and memory impairment in SAMP8 mice. (A) Effect of EA on the escape latency of mice during five consecutive days of the hidden platform test. Pc mice exhibited a longer escape latency in the training session compared to Rc mice. EA significantly reduced the escape latency in SAMP8 mice. (B) Histograms showing the swimming speed during acquisition training. (C) Histograms showing the average swim time in the target quadrant during the probe test. (D) Histograms showing the average swim time in the opposite quadrant. (E) Comparisons of the number of platform crossings in the probe trial. Data are represented as the mean \pm SEM $(n=14-16) .{ }^{\star} P<0.05,{ }^{\star \star} P<0.01$ versus $\mathrm{PC}$. with that of the hippocampus of SAMR1 mice. Furthermore, EA treatment reduced $A \beta$ expression (Figures $2 \mathbf{A}, \mathbf{B}$ ). In addition, we analyzed the levels of A $\beta 1-42$ in the hippocampus using ELISA. Consistent with the results of western blotting analysis, increased $A \beta 1-42$ levels were observed in the hippocampus in Pc mice compared with Rc mice. Moreover, Pe mice showed a significant reduction in the levels of $A \beta 1-42$ compared with $\mathrm{Pc}$ mice (Figure 2C). 


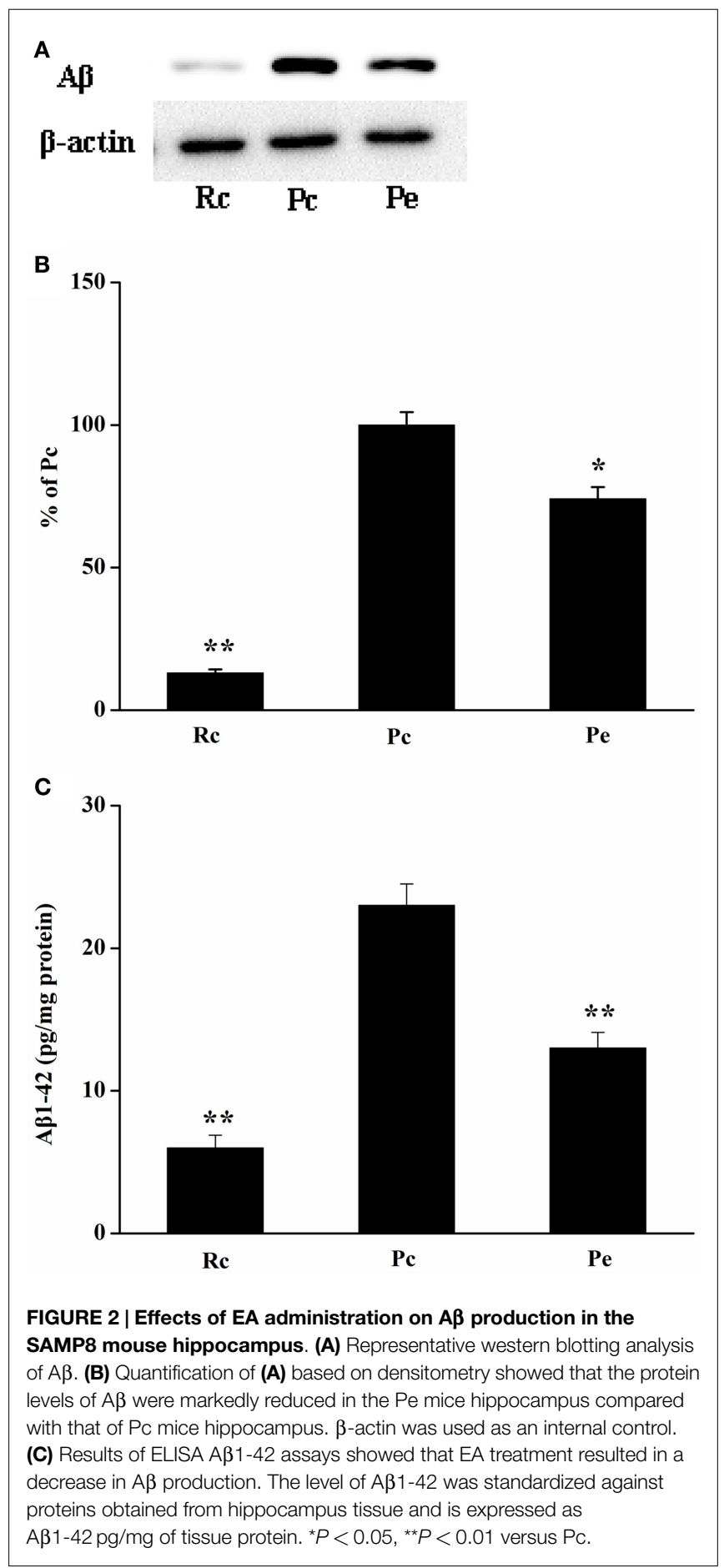

\section{EA Inhibits BACE1 Expression in the SAMP8 Mouse Hippocampus}

Because BACE1 is a key enzyme in $A \beta$ generation, reduced levels of $A \beta 1-42$ may result from decreased biogenesis of BACE1. Thus, we investigated the effects of EA treatment on BACE1 expression in SAMP8 mice. BACE1 protein was measured using western blotting analysis. We found that BACE1 expression was increased in Pc mice compared with that of Rc mice and that EA reduced BACE1 protein levels in SAMP8 mice (Figures 3A,B). To define whether
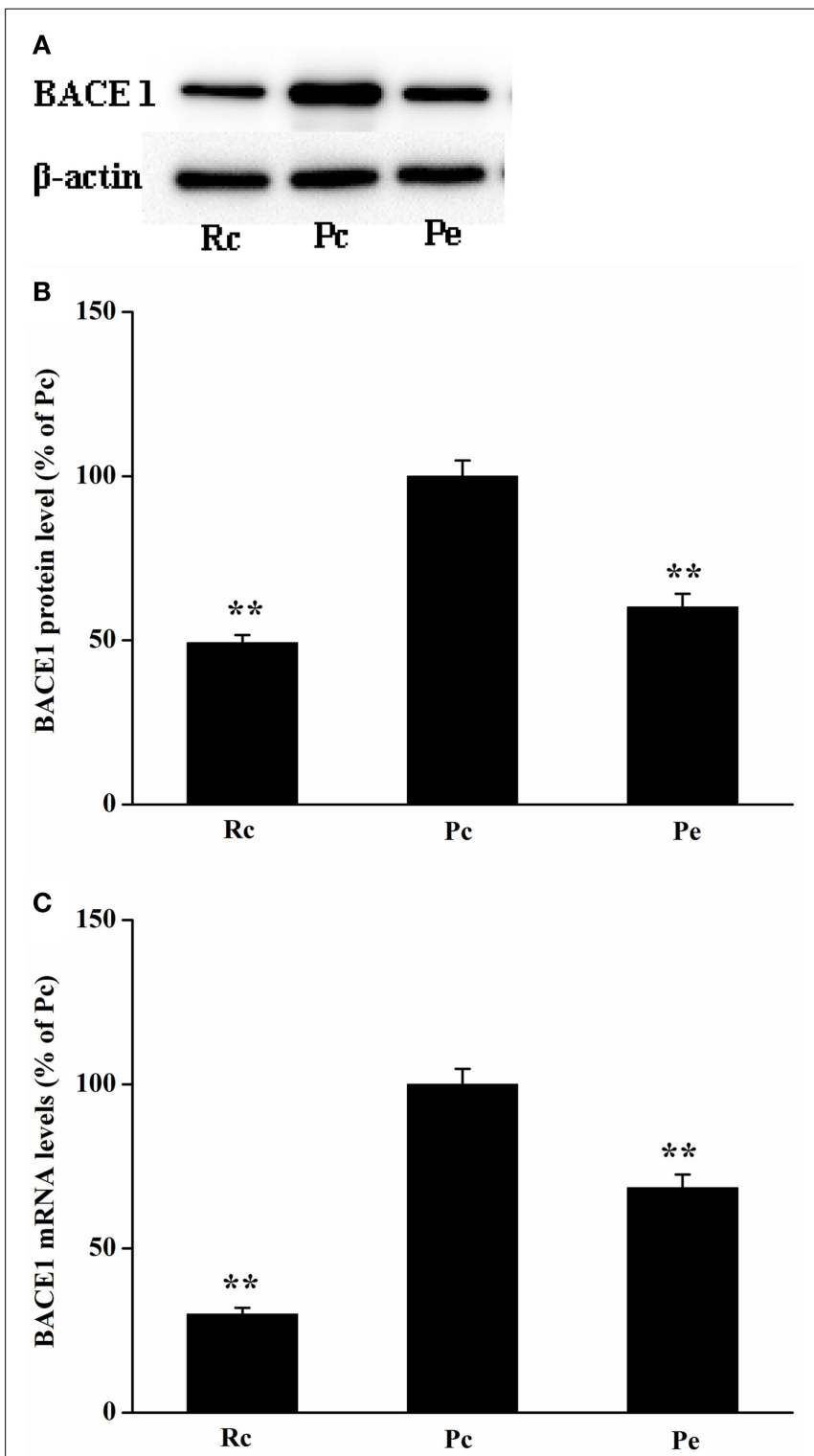

FIGURE 3 | Effects of EA treatment on BACE1 expression in SAMP8 mouse hippocampus. (A) Representative western blotting analysis of BACE1. (B) Quantitative analysis of the protein expression of BACE1 showed that the level of BACE1 protein was reduced in Pe mice compared with that of Pc mice. (C) qRT-PCR was used to measure mRNA levels. BACE1 mRNA levels were normalized against GAPDH mRNA level and compared with PC. ${ }^{\star} P<0.05,{ }^{\star \star} P<0.01$ versus $P C$

changes in BACE1 protein expression were due to alterations in BACE1 transcription, we further examined BACE1 mRNA levels using quantitative real-time reverse transcription polymerase chain reaction (qRT-PCR). As expected, EA treatment resulted in a significant decrease in BACE1 mRNA levels compared to Pc (Figure 3C).

\section{Discussion}

The present study demonstrated that EA treatment improves spatial memory in the SAMP8 mouse model of AD. Furthermore, we 
have shown that EA treatment reduces $A \beta$ production and BACE1 expression in the hippocampus of SAMP8 mice. Our data support that $\mathrm{EA}$ is effective for the treatment of $\mathrm{AD}$ in animal models.

It has been reported that compared with age-matched SAMR1 mice, cognitive impairment of SAMP8 mice could be detected beginning at 5 months of age and was severe at 7 months (Kang et al., 2014). In addition, from as early as 6 months of age, SAMP8 mice show $\mathrm{A} \beta$ deposition in the hippocampus that increases in number and extent with age (Del Valle et al., 2010; Kang et al., 2014). The tau hyperphosphorylation is significantly increased in the hippocampus of SAMP8 mice from 7 months of age (Jiang et al., 2015b) compared with SAMR1 mice. Taken together, SAMP8 mice have developed AD-like behavior and pathological hallmarks at 7 months of age. Moreover, a number of studies used 7 or 7.5-month-old SAMP8 mice to investigate the effect of EA and drug treatment on AD (Tan et al., 2014; Jiang et al., 2015a). Thus, we used SAMP8 mice at 7 months of age in this study. Additionally, Kang et al. have systematically evaluated the pathologic morphology in the hippocampus of SAMR1 and SAMP8 mice using Nissl staining, immunohistochemical staining (anti-A $\beta$ antibody), and Golgi staining at different time points (Kang et al., 2014). Previous studies have shown that acupuncture reduces neuron loss and increases cell proliferation in the hippocampus of SAMP8 mice (Cheng et al., 2008; Li et al., 2012). On the basis of these results, our study emphasizes the effect of EA on $\mathrm{A} \beta$ production and BACE1 expression in SAMP8 mice.

Amyloid plaques are one of the characteristic pathological hallmarks of $\mathrm{AD}$, and the deposition of $\mathrm{A} \beta$ is the main cause of plaque production. $A \beta$ accumulation in the brain results in a cascade of cellular changes in $\mathrm{AD}$ pathogenesis. Thus, $\mathrm{A} \beta$ reduction or clearance from the brain may be an important therapeutic strategy for prevention and treatment of AD (Jakob-Roetne and Jacobsen, 2009; Mao et al., 2012). It has been demonstrated $A \beta$ lowering capacity of anti-A $\beta$ antibodies in transgenic models of $\mathrm{AD}$ and in AD patients (Bohrmann et al., 2012; Ostrowitzki et al., 2012). To examine the mechanism of EA treatment in $\mathrm{AD}$ mice, we investigated the effects of EA on $A \beta$ expression in the hippocampus of SAMP8 mice. These results exhibited a significant increase in $A \beta$ expression in the hippocampus of 8-month-old SAMP8 mice, which was consistent with a previous study showing that SAMP8 mice demonstrate deposition of A $\beta$ from 6 months of age (Del Valle et al., 2010). EA treatment obviously decreased A $\beta$ expression. Because $A \beta 1-42$ is more cytotoxic and is more likely to aggregate and form plaques than $A \beta 1-40$ (Vattemi et al., 2009), we further examined $A \beta 1-42$ levels using ELISA in our study. Our results supported that the levels of $A \beta 1-42$ in the hippocampus were significantly increased in SAMP8 mice compared with SAMR1 mice (Li et al., 2009). In addition, EA treatment reduced the levels of $A \beta 1-42$ in SAMP8 mice. Taken together, these results suggested that $E A$ treatment might reduce $A \beta$ production.

$A \beta$, the product of the large type1 trans-membrane protein APP, is produced in a two-step proteolytic process initiated by BACE1 and followed by $\gamma$-secretase. Thus, BACE1 expression levels are strongly correlated with $A \beta$ levels. In addition, BACE1 overexpression increases $A \beta$ formation in APP transgenic mice (Bodendorf et al., 2002), whereas BACE1 knockout mice produce little or no A $\beta$ (Luo et al., 2001), indicating that BACE1 expression plays a critical role in $\mathrm{A} \beta$ biosynthesis. Thus, targeting BACE1 is the focus of $\mathrm{AD}$ research in the prevention of $\mathrm{A} \beta$ generation in AD (Sathya et al., 2012). It has been reported that several BACE1 inhibitors have entered clinical trials (May et al., 2011; Hamada and Kiso, 2013; Hilpert et al., 2013). However, a recent clinical trial with a BACE1 inhibitor had to be halted due to liver toxicity (Lahiri et al., 2014). EA has demonstrated therapeutic potential for the treatment of $\mathrm{AD}$ and has no adverse side effects. Our results showed that EA improves cognitive deficits in SAMP8 mice, which are consistent with previous studies (Cheng et al., 2008; Li et al., 2012, 2014; Wang et al., 2014a). In this study, we further examined the effects of EA on BACE1 expression in SAMP8 mice. The mRNA levels and protein levels of BACE1 are increased in the hippocampus of SAMP8 mice compared with that of the hippocampus of age-matched SAMR1 mice, which is consistent with a previous study (Orejana et al., 2015). Furthermore, our results showed that EA reduces BACE1 expression. It has been reported that targeting $\mathrm{BACE} 1$ with siRNAs reduced $\mathrm{A} \beta$ production and the neurodegenerative and behavioral deficits in an APP transgenic mouse model of AD (Singer et al., 2005). Lowering $\mathrm{BACE} 1$ expression reduced the formation of $\mathrm{A} \beta$, thereby preventing its subsequent aggregation into toxic aggregates (Citron, 2002; McConlogue et al., 2007). In addition, triptolide and icariin, the major active components extracted from a traditional Chinese herb, have been reported to inhibit BACE1 expression, attenuate $A \beta$ production and deposition, and improve cognitive deficits in transgenic mouse models of AD (Wang et al., 2014b; Zhang et al., 2014). Similar to our results, these results support the hypothesis that reduced BACE1 activity has great therapeutic potential for the treatment of $\mathrm{AD}$, and $\mathrm{BACE} 1$ is a prime therapeutic target for lowering $\mathrm{A} \beta$ levels in $\mathrm{AD}$.

We showed previously that EA activates AMPK expression and upregulates SIRT1-dependent PGC- $1 \alpha$ expression in SAMP8 mice (Dong et al., 2015). Moreover, a recent study has shown that SIRT1-PPAR $\gamma$ - PGC-1 represses BACE1 transcription and BACE1 protein levels (Wang et al., 2013). In this study, we found that EA reduced BACE1 mRNA and protein levels and decreased A $\beta$ levels. On the basis of these data, we proposed that EA upregulates SIRT1-PPAR $\gamma$ - PGC-1, which represses BACE1 expression, thereby reducing $A \beta$ production and consequently improving cognitive deficits in an AD animal model. This may represent a potential mechanism underlying EA improvement of cognitive deficits in AD.

In summary, the current study demonstrated that EA treatment reduced $A \beta$ production and BACE1 expression in the hippocampus of SAMP8 mice, thus improving learning-memory abilities. These novel findings suggest that EA treatment may have the potential to block or delay the pathological progression of $\mathrm{AD}$.

\section{Acknowledgments}

This work was supported by the National Natural Science Foundation of China (project 81102625), the Natural Science Foundation of Fujian Province Grants (project 2012J05154), Program for New Century Excellent Talents in Fujian Province University, and study abroad scholarships of Fujian Province. 


\section{References}

Bayod, S., Felice, P., Andres, P., Rosa, P., Camins, A., Pallas, M., et al. (2015). Downregulation of canonical Wnt signaling in hippocampus of SAMP8 mice. Neurobiol. Aging 36, 720-729. doi:10.1016/j.neurobiolaging

Bodendorf, U., Danner, S., Fischer, F., Stefani, M., Sturchler-Pierrat, C., Wiederhold, K. H., et al. (2002). Expression of human beta-secretase in the mouse brain increases the steady-state level of beta-amyloid. J. Neurochem. 80, 799-806. doi:10.1046/j.0022-3042.2002.00770.x

Bohrmann, B., Baumann, K., Benz, J., Gerber, F., Huber, W., Knoflach, F., et al. (2012). Gantenerumab: a novel human anti-Abeta antibody demonstrates sustained cerebral amyloid-beta binding and elicits cell-mediated removal of human amyloid-beta. J. Alzheimers Dis. 28, 49-69. doi:10.3233/ JAD-2011-110977

Cheng, H., Yu, J., Jiang, Z., Zhang, X., Liu, C., Peng, Y., et al. (2008). Acupuncture improves cognitive deficits and regulates the brain cell proliferation of SAMP8 mice. Neurosci. Lett. 432, 111-116. doi:10.1016/j.neulet.2007.12.009

Cheng, X. R., Zhou, W. X., and Zhang, Y. X. (2014). The behavioral, pathological and therapeutic features of the senescence-accelerated mouse prone 8 strain as an Alzheimer's disease animal model. Ageing Res. Rev. 13, 13-37. doi:10.1016/j. arr.2013.10.002

Chon, T. Y., and Lee, M. C. (2013). Acupuncture. Mayo Clin. Proc. 88, 1141-1146. doi:10.1016/j.mayocp.2013.06.009

Citron, M. (2002). Emerging Alzheimer's disease therapies: inhibition of beta-secretase. Neurobiol. Aging 23, 1017-1022. doi:10.1016/S0197-4580(02) 00122-7

Coulson, D. T., Beyer, N., Quinn, J. G., Brockbank, S., Hellemans, J., Irvine, G. B., et al. (2010). BACE1 mRNA expression in Alzheimer's disease postmortem brain tissue. J. Alzheimers Dis. 22, 1111-1122. doi:10.3233/JAD-2010-101254

Del Valle, J., Duran-Vilaregut, J., Manich, G., Casadesus, G., Smith, M. A., Camins, A., et al. (2010). Early amyloid accumulation in the hippocampus of SAMP8 mice. J. Alzheimers Dis. 19, 1303-1315. doi:10.3233/JAD-2010-1321

Dong, W., Guo, W., Zheng, X., Wang, F., Chen, Y., Zhang, W., et al. (2015). Electroacupuncture improves cognitive deficits associated with AMPK activation in SAMP8 mice. Metab. Brain Dis. 30, 777-784. doi:10.1007/s11011-014-9641-1

Fukumoto, H., Cheung, B. S., Hyman, B. T., and Irizarry, M. C. (2002). Betasecretase protein and activity are increased in the neocortex in Alzheimer disease. Arch. Neurol. 59, 1381-1389. doi:10.1001/archneur.59.9.1381

Hamada, Y., and Kiso, Y. (2013). Advances in the identification of beta-secretase inhibitors. Expert Opin. Drug Discov. 8, 709-731. doi:10.1517/17460441.2013. 784267

Harada, H., Tamaoka, A., Ishii, K., Shoji, S., Kametaka, S., Kametani, F., et al. (2006). Beta-site APP cleaving enzyme 1 (BACE1) is increased in remaining neurons in Alzheimer's disease brains. Neurosci. Res. 54, 24-29. doi:10.1016/j.neures.2005. 10.001

Hardy, J., and Selkoe, D. J. (2002). The amyloid hypothesis of Alzheimer's disease: progress and problems on the road to therapeutics. Science 297, 353-356. doi:10. 1126/science.1072994

Hilpert, H., Guba, W., Woltering, T. J., Wostl, W., Pinard, E., Mauser, H., et al. (2013). beta-Secretase (BACE1) inhibitors with high in vivo efficacy suitable for clinical evaluation in Alzheimer's disease. J. Med. Chem. 56, 3980-3995. doi:10.1021/jm400225m

Holsinger, R. M., McLean, C. A., Beyreuther, K., Masters, C. L., and Evin, G. (2002). Increased expression of the amyloid precursor beta-secretase in Alzheimer's disease. Ann. Neurol. 51, 783-786. doi:10.1002/ana.10208

Jakob-Roetne, R., and Jacobsen, H. (2009). Alzheimer's disease: from pathology to therapeutic approaches. Angew. Chem. Int. Ed. Engl. 48, 3030-3059. doi:10.1002/ anie. 200802808

Jiang, J., Gao, K., Zhou, Y., Xu, A., Shi, S., Liu, G., et al. (2015a). Electroacupuncture treatment improves learning-memory ability and brain glucose metabolism in a mouse model of Alzheimer's disease: using morris water maze and micro-PET. Evid. Based Complement. Altern. Med. 2015, 142129. doi:10.1155/ $2015 / 142129$

Jiang, T., Zhang, Y. D., Zhou, J. S., Zhu, X. C., Tian, Y. Y., Zhao, H. D., et al. (2015b). Angiotensin-(1-7) is reduced and inversely correlates with tau hyperphosphorylation in animal models of Alzheimer's disease. Mol. Neurobiol. doi:10.1007/ s12035-015-9260-9

Kang, L., Li, S., Xing, Z., Li, J., Su, Y., Fan, P., et al. (2014). Dihydrotestosterone treatment delays the conversion from mild cognitive impairment to Alzheimer's disease in SAMP8 mice. Horm. Behav. 65, 505-515. doi:10.1016/j.yhbeh.2014. 03.017

Katsouri, L., Parr, C., Bogdanovic, N., Willem, M., and Sastre, M. (2011). PPAR $\gamma$ co-activator-1alpha (PGC-1alpha) reduces amyloid-beta generation through a PPAR $\gamma$-dependent mechanism. J. Alzheimers Dis. 25, 151-162. doi:10.3233/ JAD-2011-101356

Lahiri, D. K., Maloney, B., Long, J. M., and Greig, N. H. (2014). Lessons from a BACE1 inhibitor trial: off-site but not off base. Alzheimers Dement. 10, S411-S419. doi:10.1016/j.jalz.2013.11.004

Li, G., Zhang, X., Cheng, H., Shang, X., Xie, H., Zhang, X., et al. (2012). Acupuncture improves cognitive deficits and increases neuron density of the hippocampus in middle-aged SAMP8 mice. Acupunct. Med. 30, 339-345. doi:10.1136/ acupmed-2012-010180

Li, Q., Zhao, H. F., Zhang, Z. F., Liu, Z. G., Pei, X. R., Wang, J. B., et al. (2009). Longterm green tea catechin administration prevents spatial learning and memory impairment in senescence-accelerated mouse prone- 8 mice by decreasing Abeta1-42 oligomers and upregulating synaptic plasticity-related proteins in the hippocampus. Neuroscience 163, 741-749. doi:10.1016/j.neuroscience.2009. 07.014

Li, R., Lindholm, K., Yang, L. B., Yue, X., Citron, M., Yan, R., et al. (2004). Amyloid beta peptide load is correlated with increased beta-secretase activity in sporadic Alzheimer's disease patients. Proc. Natl. Acad. Sci. U.S.A. 101, 3632-3637. doi:10. 1073/pnas.0205689101

Li, X., Guo, F., Zhang, Q., Huo, T., Liu, L., Wei, H., et al. (2014). Electroacupuncture decreases cognitive impairment and promotes neurogenesis in the APP/PS1 transgenic mice. BMC Complement. Altern. Med. 14:37-46. doi:10. 1186/1472-6882-14-37

Li, Y., Zhou, W., Tong, Y., He, G., and Song, W. (2006). Control of APP processing and Abeta generation level by BACE1 enzymatic activity and transcription FASEB J. 20, 285-292. doi:10.1096/fj.05-4986com

Luo, Y., Bolon, B., Kahn, S., Bennett, B. D., Babu-Khan, S., Denis, P., et al. (2001). Mice deficient in BACE1, the Alzheimer's beta-secretase, have normal phenotype and abolished beta-amyloid generation. Nat. Neurosci. 4, 231-232. doi:10.1038/85059

Manich, G., Mercader, C., del Valle, J., Duran-Vilaregut, J., Camins, A., Pallas, M., et al. (2011). Characterization of amyloid-beta granules in the hippocampus of SAMP8 mice. J. Alzheimers Dis. 25, 535-546. doi:10.3233/JAD-2011-101713

Mao, P., Manczak, M., Calkins, M. J., Truong, Q., Reddy, T. P., Reddy, A. P., et al. (2012). Mitochondria-targeted catalase reduces abnormal APP processing, amyloid beta production and BACE1 in a mouse model of Alzheimer's disease: implications for neuroprotection and lifespan extension. Hum. Mol. Genet. 21, 2973-2990. doi:10.1093/hmg/dds128

Marwarha, G., Raza, S., Meiers, C., and Ghribi, O. (2014). Leptin attenuates BACE1 expression and amyloid-beta genesis via the activation of SIRT1 signaling pathway. Biochim. Biophys. Acta 1842, 1587-1595. doi:10.1016/j.bbadis.2014.05 015

May, P. C., Dean, R. A., Lowe, S. L., Martenyi, F., Sheehan, S. M., Boggs, L. N., et al. (2011). Robust central reduction of amyloid-beta in humans with an orally available, non-peptidic beta-secretase inhibitor. J. Neurosci. 31, 16507-16516. doi:10.1523/JNEUROSCI.3647-11.2011

McConlogue, L., Buttini, M., Anderson, J. P., Brigham, E. F., Chen, K. S., Freedman, S. B., et al. (2007). Partial reduction of BACE1 has dramatic effects on Alzheimer plaque and synaptic pathology in APP transgenic mice. J. Biol. Chem. 282, 26326-26334. doi:10.1074/jbc.M611687200

Menting, K. W., and Claassen, J. A. (2014). beta-secretase inhibitor; a promising novel therapeutic drug in Alzheimer's disease. Front. Aging Neurosci. 6:165. doi:10.3389/fnagi.2014.00165

Ohno, M., Sametsky, E. A., Younkin, L. H., Oakley, H., Younkin, S. G., Citron, M., et al. (2004). BACE1 deficiency rescues memory deficits and cholinergic dysfunction in a mouse model of Alzheimer's disease. Neuron 41, 27-33. doi:10. 1016/S0896-6273(03)00810-9

Orejana, L., Barros-Minones, L., Jordan, J., Cedazo-Minguez, A., Tordera, R. M., Aguirre, N., et al. (2015). Sildenafil decreases BACE1 and cathepsin B levels and reduces APP amyloidogenic processing in the SAMP8 mouse. J. Gerontol. A Biol. Sci. Med. Sci. 70, 675-685. doi:10.1093/gerona/glu106

Ostrowitzki, S., Deptula, D., Thurfjell, L., Barkhof, F., Bohrmann, B., Brooks, D. J. et al. (2012). Mechanism of amyloid removal in patients with Alzheimer disease treated with gantenerumab. Arch. Neurol. 69, 198-207. doi:10.1001/archneurol. 2011.1538 
Pallas, M., Camins, A., Smith, M. A., Perry, G., Lee, H. G., and Casadesus, G. (2008). From aging to Alzheimer's disease: unveiling "the switch" with the senescence-accelerated mouse model (SAMP8). J. Alzheimers Dis. 15, 615-624.

Sathya, M., Premkumar, P., Karthick, C., Moorthi, P., Jayachandran, K. S., and Anusuyadevi, M. (2012). BACE1 in Alzheimer's disease. Clin. Chim. Acta 414, 171-178. doi:10.1016/j.cca.2012.08.013

Selkoe, D. J., and Schenk, D. (2003). Alzheimer's disease: molecular understanding predicts amyloid-based therapeutics. Annu. Rev. Pharmacol. Toxicol. 43, 545-584. doi:10.1146/annurev.pharmtox.43.100901.140248

Singer, O., Marr, R. A., Rockenstein, E., Crews, L., Coufal, N. G., Gage, F. H., et al. (2005). Targeting BACE1 with siRNAs ameliorates Alzheimer disease neuropathology in a transgenic model. Nat. Neurosci. 8, 1343-1349. doi:10.1038/ nn1531

Takeda, T. (1999). Senescence-accelerated mouse (SAM): a biogerontological resource in aging research. Neurobiol. Aging 20, 105-110. doi:10.1016/ S0197-4580(99)00008-1

Takeda, T. (2009). Senescence-accelerated mouse (SAM) with special references to neurodegeneration models, SAMP8 and SAMP10 mice. Neurochem. Res. 34, 639-659. doi:10.1007/s11064-009-9922-y

Tan, M. S., Yu, J. T., Jiang, T., Zhu, X. C., Guan, H. S., and Tan, L. (2014). IL12/23 p40 inhibition ameliorates Alzheimer's disease-associated neuropathology and spatial memory in SAMP8 mice. J. Alzheimers Dis. 38, 633-646. doi:10.3233/ JAD- 131148

Vattemi, G., Nogalska, A., King Engel, W., D’Agostino, C., Checler, F., and Askanas, V. (2009). Amyloid-beta42 is preferentially accumulated in muscle fibers of patients with sporadic inclusion-body myositis. Acta Neuropathol. 117, 569-574. doi:10.1007/s00401-009-0511-6

Wang, F., Zhong, H., Li, X., Peng, Y., Kinden, R., Liang, W., et al. (2014a). Electroacupuncture attenuates reference memory impairment associated with astrocytic NDRG2 suppression in APP/PS1 transgenic mice. Mol. Neurobiol. 50, 305-313. doi:10.1007/s12035-013-8609-1

Wang, Q., Xiao, B., Cui, S., Song, H., Qian, Y., Dong, L., et al. (2014b). Triptolide treatment reduces Alzheimer's disease (AD)-like pathology through inhibition of BACE1 in a transgenic mouse model of AD. Dis. Model Mech. 7, 1385-1395. doi:10.1242/dmm.018218
Wang, Z., Liang, P., Zhao, Z., Han, Y., Song, H., Xu, J., et al. (2014c). Acupuncture modulates resting state hippocampal functional connectivity in Alzheimer disease. PLoS ONE 9:e91160. doi:10.1371/journal.pone.0091160

Wang, R., Li, J. J., Diao, S., Kwak, Y. D., Liu, L., Zhi, L., et al. (2013). Metabolic stress modulates Alzheimer's beta-secretase gene transcription via SIRT1PPARgamma-PGC-1 in neurons. Cell Metab. 17, 685-694. doi:10.1016/j.cmet. 2013.03.016

Wang, Z., Nie, B., Li, D., Zhao, Z., Han, Y., Song, H., et al. (2012). Effect of acupuncture in mild cognitive impairment and Alzheimer disease: a functional MRI study. PLoS ONE 7:e42730. doi:10.1371/journal.pone.0042730

Yan, R., and Vassar, R. (2014). Targeting the beta secretase BACE1 for Alzheimer's disease therapy. Lancet Neurol. 13, 319-329. doi:10.1016/S1474-4422(13) 70276-X

Zhang, L., Shen, C., Chu, J., Zhang, R., Li, Y., and Li, L. (2014). Icariin decreases the expression of APP and BACE-1 and reduces the beta-amyloid burden in an APP transgenic mouse model of Alzheimer's disease. Int. J. Biol. Sci. 10, 181-191. doi:10.7150/ijbs.6232

Zhang, Y. W., and Xu, H. (2007). Molecular and cellular mechanisms for Alzheimer's disease: understanding APP metabolism. Curr. Mol. Med. 7, 687-696. doi:10.2174/156652407782564462

Zhou, J. W., Cheng, X. R., Cheng, J. P., Zhou, W. X., and Zhang, Y. X. (2012). The activity and mRNA expression of beta-secretase, cathepsin D, and cathepsin $B$ in the brain of senescence-accelerated mouse. J. Alzheimers Dis. 28, 471-480. doi:10.3233/JAD-2011-111469

Conflict of Interest Statement: The authors declare that the research was conducted in the absence of any commercial or financial relationships that could be construed as a potential conflict of interest.

Copyright (c) 2015 Dong, Wang, Chen, Zheng, Xie, Guo and Shi. This is an open-access article distributed under the terms of the Creative Commons Attribution License (CC $B Y)$. The use, distribution or reproduction in other forums is permitted, provided the original author(s) or licensor are credited and that the original publication in this journal is cited, in accordance with accepted academic practice. No use, distribution or reproduction is permitted which does not comply with these terms. 